\title{
Development of Benthic Sampling Methods for the Coral Reef Assessment and Monitoring Program (CRAMP) in Hawai ${ }^{i}{ }^{1}$
}

\author{
Eric Brown, ${ }^{2,5}$ Evelyn Cox, ${ }^{2}$ Paul 7okiel, ${ }^{2}$ Ku ulei Rodgers, ${ }^{2}$ William Smith, ${ }^{2}$ Brian Tissot, ${ }^{3}$ \\ Steve L. Coles, ${ }^{4}$ and Fonatban Hultquist ${ }^{5}$
}

\begin{abstract}
The Coral Reef Assessment and Monitoring Program (CRAMP) of Hawai' $i$ was established in 1998 to monitor long-term changes in coral reef benthic communities around the state. Development of the methodology involved analysis of results from previous monitoring programs in Hawai' $i$ to determine precision and statistical power of various methods to detect change. Additional field trials were conducted to examine factors such as repeatability, appropriate transect length, number of transects, number of samples per transect, cover estimation techniques, observer variation, as well as time and financial constraints. Benthic monitoring methods used previously in Hawai' $\mathrm{i}$ generally showed low statistical power for detecting change due to low precision and small sample size. Field trials indicated that repeatability of conventional techniques using transects or quadrats had high variation and consequently low statistical power unless efforts were made to reposition the sampling units with greater precision. Longer transects (e.g., 25 and $50 \mathrm{~m}$ ) had higher variability than shorter transects (e.g., $10 \mathrm{~m}$ ), suggesting that smaller sampling units were more appropriate for the habitats sampled. Variability among observers analyzing the same data was low in comparison with other sources of error. Visual estimation techniques showed low initial cost but were inefficient per survey. Digital video required the highest initial monetary investment but yielded the greatest quantity of data per survey with sufficient quality. The cost effectiveness of the digital video method compared with other techniques increased with more surveys and in more remote situations where logistical expenses were incurred. A within-habitat stratified random sampling design was implemented for the CRAMP design. Fixed transects were chosen to reduce temporal variance and allowed efficient resurveying under the high-wave-energy field conditions typically found in Hawai'i. The method was designed to detect an absolute change of $10 \%$ in benthic cover with high statistical power using 50 points per frame, 20-30 frames per transect, and 8-10 transects per depth. Fixed photoquadrats with high precision and high resolution were included in the design to allow detailed monitoring of coral/algal growth, recruitment, and mortality.
\end{abstract}

${ }^{1}$ This project was partially supported by the Hawai' $i$ Coral Reef Initiative and USGS Cooperative Agreement 98WRAG1030. Manuscript accepted 27 May 2003.

2 Hawai'i Institute of Marine Biology, University of Hawai'i at Mānoa, P.O. Box 1346, Kāne'ohe, Hawai'i

Pacific Science (2004), vol. 58, no. 2:145-158

(C) 2004 by University of Hawai'i Press
96744 (E-mail: Pavona@aol.com [Brown], fcox@hawaii .edu [Cox], jokiel@hawaii.edu [Jokiel], kuuleir@hawaii .edu [Rodgers], wsmith@hawaii.edu [Smith]).

3 Washington State University-Vancouver, 14204 NE Salmon Creek Avenue, Vancouver, Washington 98686 (E-mail: tissot@vancouver.wsu.edu).

${ }^{4}$ Department of Natural Sciences, Bernice P. Bishop Museum, P.O. Box 19000, Honolulu, Hawai'i 96817 (E-mail: slcoles@bishopmuseum.org).

${ }^{5}$ Pacific Whale Foundation, 300 Mā'alaea Road, no. 211, Wailuku, Hawai‘i 96793-9940 (E-mail: jonathan@ pacificwhale.org). 
Hawailan coral reefs are subjected to a variety of natural and anthropogenic stresses (Grigg and Dollar 1990). Natural factors, such as acute wave disturbances, can affect the shallow-water reef communities at a small spatial and temporal scale (Dollar 1993). In contrast, chronic disturbances, such as nonpoint source pollution, can change communities over longer time periods that may be difficult to ascertain (Pastorok and Bilyard 1985). Establishing cause and effect relationships is challenging under these dynamic conditions without knowing the location and rate of change. Therefore, long-term monitoring is necessary to understand the role of natural and anthropogenic processes on changes in assemblages (Hughes and Connell 1999).

Long-term monitoring involves repeated surveys of organisms and/or environmental parameters at selected sites over time (Rogers et al. 1994). Documenting changes in the community structure at various spatial and temporal scales using a well-designed monitoring program can assess the "condition" (i.e., deteriorating, improving, undergoing a phase shift, etc.) of various reefs and lead to research activities that examine causal links among the various factors (Hughes 1996, Done and Reichelt 1998). Examples of ongoing long-term monitoring programs include the Environmental Protection Agency (EPA) Coral/Hardbottom Monitoring Project (Wheaton et al. 1999) and the National Oceanic and Atmospheric AdministrationUniversity of North Carolina (NOAA-UNC) Wilmington Monitoring Program in Florida (Miller and Swanson 1999), the Caribbean Coastal Marine Productivity (CARICOMP) Program (Woodley and Linton 1999) and Atlantic-Gulf Reef Assessment (Ginsburg et al. 1999) in the Caribbean, and the Australian Institute of Marine Science (AIMS) Longterm Monitoring Program off the Great Barrier Reef (Sweatman 1997). Each program has developed methodologies suitable to its region.

Long-term coral reef monitoring projects have been initiated previously in Hawai'i to detect change in coral cover at several locations, including Kahe Point (Coles 1998) and
Hanauma Bay (C. L. Hunter, unpubl. data) on O'ahu; Honolua Bay, Kahekili, Puamana, and Olowalu on Maui (Brown 1999); and Molokini Island (B.T., unpubl. data). Previous monitoring programs in Hawaili were generally undertaken using various methods without any critical evaluation of the method employed. Differences in methods used in these studies make it difficult to integrate the results and compare coral population trends at a larger spatial scale such as islandwide or statewide.

The primary objective of CRAMP is to evaluate the condition of the reef communities throughout the main Hawaiian Islands by describing spatial and temporal variation in Hawaiian reef communities in relation to natural and anthropogenic forcing functions. Sites were selected on the basis of existing data, management concerns, degree of perceived environmental degradation and/or recovery, level of management protection, and extent of wave exposure. The CRAMP monitoring sites were selected in a process that extended over several years (1997-2000) and involved continual interaction between managers and research scientists. Additional criteria are described in more detail at http:// cramp.wcc.hawaii.edu. These CRAMP sites will continue to be monitored at regular intervals over the next century and will form the basis for evaluating long-term change on Hawaiian coral reefs. Initial results of the monitoring program are presented in this issue in Jokiel et al. (2004).

Evaluation of various methods is an important precursor to initiating monitoring programs (Fairweather 1991). This report describes the development of the CRAMP sampling protocol in which several sampling protocols were evaluated to develop an appropriate method that could detect an absolute change of $10 \%$ in coral cover with high statistical power $(P>0.8)$. Use of statistical power as a tool to evaluate the appropriateness of a selected sampling design to detect change is not widely practiced. As far as we can determine, only the Great Barrier Reef monitoring program addressed statistical power before initiating studies (Sweatman 1997). Determining the appropriate sampling 
design for the CRAMP statewide monitoring program was an iterative process that progressed along two simultaneous tracks. First, methods and results from previous studies were evaluated for precision and statistical power to determine if any of these procedures could be used in the CRAMP protocol for detecting change in benthic communities. Second, field tests were conducted to evaluate precision, transect length, number of transects (sampling units), number of frames (subsamples), cover estimation techniques, observer variation, and time and monetary constraints. Statistical power was also calculated for the various field tests and used as a guide to select an appropriate protocol for detecting change.

\section{MATERIALS AND METHODS}

\section{Study Areas and Data Sources}

The study sites were located within the main Hawaiian Islands and focused on areas where previous monitoring studies had been conducted (Figure 1) and sampled more than twice (Table 1). These included the following: (1) Kāne'ohe Bay, O'ahu, sites surveyed by Maragos, Holthuis, Evans, and Hunter (Maragos 1972, Evans et al. 1986, Hunter and Evans 1993) using visual estimation in 1- $\mathrm{m}^{2}$ quadrats to determine percentage cover. (2) Kahe Point, O'ahu, surveyed by Coles (1998) using 40 fixed photoquadrats at four sites sampled annually since 1980 to document changes in coral cover. Coral cover for these photoquads was estimated from a grid of 500 evenly spaced points placed on the projected photograph. (3) Hanauma Bay, O'ahu, sampled by C. L. Hunter (unpubl. data) annually using six analog video transects with frame capture and random point projections. Ten frames were used per transect with 50 points per frame. (4) West Maui, data obtained by the Pacific Whale Foundation monitoring program along the West Maui coastline since 1993 using Earthwatch volunteers (Brown 1999). Sites included Honolua Bay, Kahekili, Puamana, and Olowalu on Maui. The benthic methodology used a visual planar point intercept method (Reed 1980) with a $1-\mathrm{m}^{2}$ polyvinyl chloride (PVC) quadrat to survey random plots along six 50-m transects at each site ( $n=3$ at each reef). The sampling unit was the transect with quadrats treated as subsamples. (5) Molokini Island, monitored by the University of Hawai' $i$ at Hilo in conjunction with the State of Hawai' $i$, Division of Aquatic Resources (DAR), from 1996 to 1998 . Three zones (east, middle, and west) were monitored twice a year using one $50-\mathrm{m}$ transect at three depths $(15 \mathrm{~m}, 40 \mathrm{~m}$, $60 \mathrm{~m}$ ) within each zone. Sampling was conducted using a $0.5-\mathrm{m}^{2}$ photoquadrat frame containing a camera (Nikonos $V$ ) with dual strobes elevated $0.75 \mathrm{~m}$ above the substrate. Thirty-six randomly placed exposures were taken on each transect and analyzed using 50 random points per photograph to document percentage cover.

Current field tests evaluated transect lines of different lengths $(10 \mathrm{~m}, 25 \mathrm{~m}$, and $50 \mathrm{~m})$ using visual estimation quadrats (Ohlhorst et al. 1988), planar point intercept quadrats (Reed 1980), photoquadrat (Coyer and Witman 1990), and video (Aronson et al. 1994) techniques to measure coral cover (Table 2). Sampling was repeated at several locations to estimate sampling precision, observer variability, and statistical power to detect change.

Photoquadrats were compared with planar point intercept and visual estimation quadrats collected 2 to 4 December 1998 in Kāne'ohe Bay, O'ahu. Transect lengths of $10 \mathrm{~m}$ and $25 \mathrm{~m}$ were used to estimate sampling error as a function of transect length. The same transects were resampled from 17 to $18 \mathrm{De}$ cember 1998 using photoquadrats to estimate observer variability and examine the precision in relocating the transect by deploying pins every $2 \mathrm{~m}$ along the line. Photoquadrat data from Molokini were acquired across two sampling days from 10 to 11 October 1998 using a $50-\mathrm{m}$ transect to estimate sampling error on the same transect.

The quadrat grid used for visual estimation and planar point intercept was $1 \mathrm{~m}^{2}$ and consisted of $1.25-\mathrm{cm}$ PVC tubing fitted with nylon line spaced $10 \mathrm{~cm}$ apart to form a grid with 100 sampling blocks and 81 intersections. Quadrat size of $1 \mathrm{~m}^{2}$ was selected based 


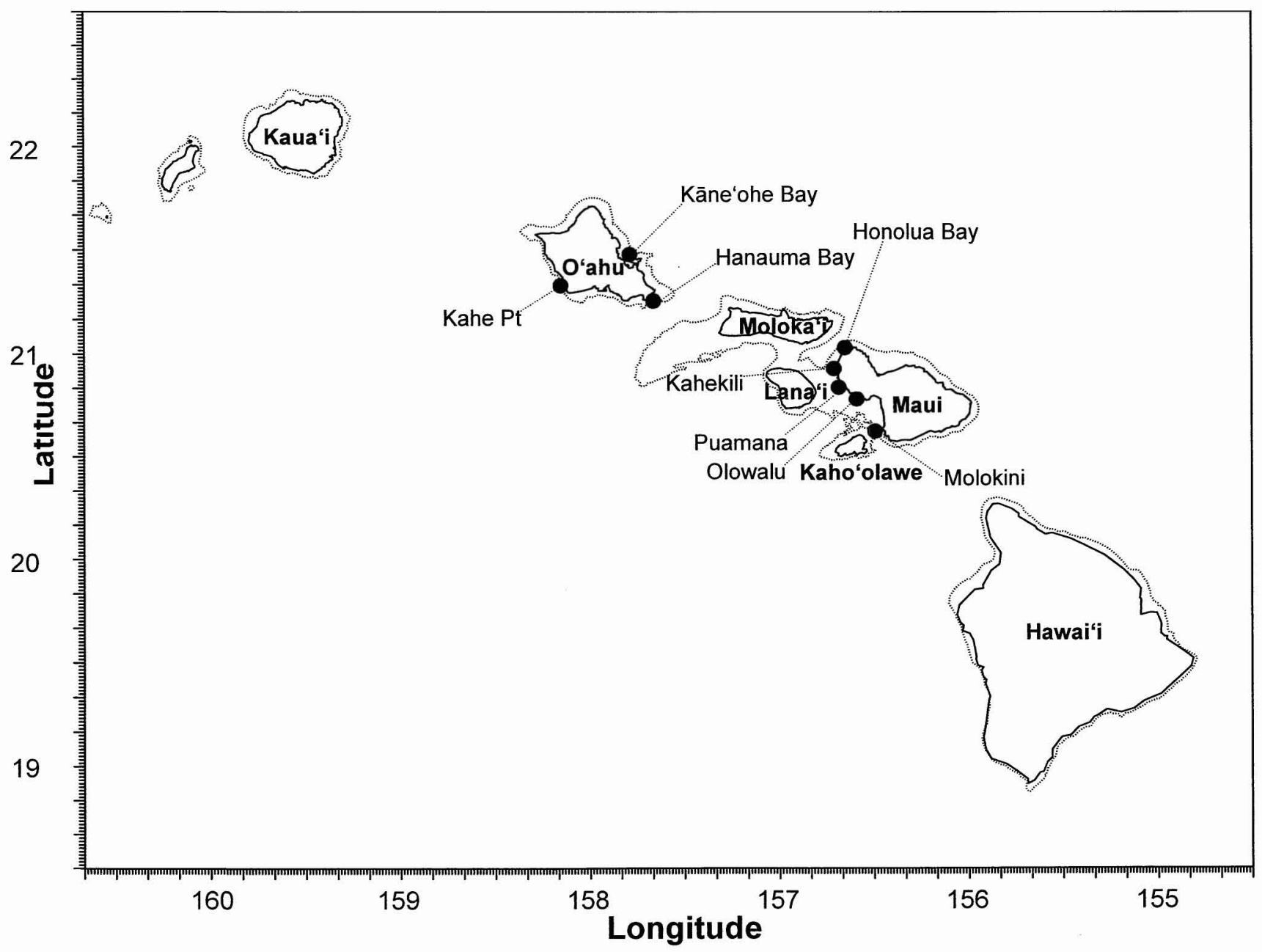

FIGURE 1. Study sites used in the evaluation of historical and current methods. 
TABLE 1

Previous Data Examined for This Study

\begin{tabular}{lllllr}
\hline \hline Method & Study Site $^{a}$ & $\begin{array}{c}\text { Depth } \\
(\mathrm{m})\end{array}$ & $\begin{array}{c}\text { Transect } \\
\text { Length }\end{array}$ & $\begin{array}{c}\text { Sampling } \\
\text { Frequency }\end{array}$ & $\begin{array}{c}\text { Sampling } \\
\text { Period }\end{array}$ \\
\hline Planar point intercept & Honolua $^{1}$ & 3 & $50 \mathrm{~m}$ & $8 \times / \mathrm{yr}$ & $1994-1998$ \\
& Kahekili $^{1}$ & 6 & $50 \mathrm{~m}$ & $8 \times / \mathrm{yr}$ & $1994-1998$ \\
& Puamana $^{1}$ & 3,13 & $50 \mathrm{~m} / \mathrm{yr}$ & $1994-1998$ \\
Photoquadrat & Olowalu $^{1}$ & 3,7 & $50 \mathrm{~m}$ & $8 \times 1 \mathrm{yr}$ & $1994-1998$ \\
Fixed photoquadrat & Molokini $^{2}$ & $5,12,18$ & $50 \mathrm{~m}$ & $2 \mathrm{x} / \mathrm{yr}$ & $1996-1998$ \\
& Kahe $^{3}$ & $3,4,5$ & $10 \mathrm{frames} / \mathrm{site}$ & $1 \mathrm{x} / \mathrm{yr}$ & $1980-1997$ \\
\hline
\end{tabular}

${ }^{a}$ Study references: ${ }^{1}$ Brown 1999; ${ }^{2}$ University of Hawai'i at Hilo and Division of Aquatic Resources, unpubl. data; ${ }^{3}$ Coles 1998.

TABLE 2

Methods and Sites Examined in This Study

\begin{tabular}{|c|c|c|c|c|c|c|}
\hline Method & Study Site & Study & $\begin{array}{l}\text { Depth } \\
\text { (m) }\end{array}$ & $\begin{array}{c}\text { Transect } \\
\text { Length }(\mathrm{m})\end{array}$ & $\begin{array}{l}\text { Sampling } \\
\text { Frequency }\end{array}$ & $\begin{array}{l}\text { Sampling } \\
\text { Period }\end{array}$ \\
\hline \multicolumn{7}{|l|}{ Precision } \\
\hline $\begin{array}{l}\text { Planar point } \\
\text { intercept quadrat }\end{array}$ & Kāne'ohe & This study & 3 & $10-25$ & $2 \mathrm{x}$ & 1998-1999 \\
\hline \multirow{3}{*}{ Photoquadrat } & Kāne'ohe & This study & 3 & $10-25$ & $2 \mathrm{x}$ & 1998-1999 \\
\hline & Molokini & $\begin{array}{l}\text { University of } \\
\text { Hawai'i at Hilo }\end{array}$ & 5 & 50 & $2 \mathrm{x}$ & $1996-1998$ \\
\hline & Hanauma & This study & 3 & 10 & $1 \mathrm{x}$ & 1999 \\
\hline Digital video & Hanauma & This study & 3,10 & 10 & $2 \mathrm{x}$ & 1999 \\
\hline \multicolumn{7}{|l|}{ Observer variability } \\
\hline Visual estimation & Kāne'ohe & This study & $1,3,10$ & $15-25$ & $1 \mathrm{x}$ & 1999 \\
\hline Photoquadrat & Kāne'ohe & This study & 3 & $10-25$ & $2 \mathrm{x}$ & 1999 \\
\hline
\end{tabular}

on prior studies and the size of the organisms being documented (Rogers et al. 1994). Each quadrat was placed randomly along transect lines of 10,25 , and $50 \mathrm{~m}$ from a fixed reference mark. Different species of coral as well as the substrate type found within the sampling blocks (visual estimation) or underneath each intersection (planar point intercept) were recorded on underwater slates. In the visual estimation technique the number of blocks occupied by each substrate type were recorded at a resolution of $0.5 \%$. In the planar point intercept method the total number of points intersecting each type of substrate was counted and divided by 81 to generate a percentage cover value.

The photoquadrat consisted of a PVC frame that supported a camera (Nikonos V) with a $15-\mathrm{mm}$ lens and dual strobe setup. The camera was $0.7 \mathrm{~m}$ above the substrate and captured $0.5 \mathrm{~m}^{2}$ of benthic area. Use of the $15-\mathrm{mm}$ lens produced a slight distortion on the edges of the image, but this allowed detection of smaller recruits and was consistent among samples and time periods. Further, the $15-\mathrm{mm}$ lens effectively reduces the height of the photoquadrat, making it more compact and stable in conditions of high wave motion typical of Hawaiian inshore reefs. Placement of the photoquad was determined randomly along transect lines of 10,25 , and $50 \mathrm{~m}$. Two methods of line placement were utilized: fixed endpoints and fixed endpoints with pins along the transect at $2-\mathrm{m}$ intervals to reduce variability in line movement. Images were projected onto a screen with 50 random points. Percentage cover was determined by identifying the number of points on each substrate type, dividing by 50 , and multiplying by 100. 


\section{Precision of Digital Video Transects}

Digital video was evaluated at the Hanauma Bay, O'ahu, Marine Life Conservation District using a camcorder (Sony VCX-1000) in a housing (Amphico). The two sampling dates were 5 January 1999 and 30 March 1999. It was assumed (and subsequently verified by $4 \mathrm{yr}$ of monitoring) that overall coral cover would not change dramatically during that time period. On the first date, six $10-\mathrm{m}$ transects were deployed over the existing transects (C. L. Hunter, unpubl. data) at two depths $(3 \mathrm{~m}$ and $10 \mathrm{~m})$ and videotaped at a distance approximately $0.5 \mathrm{~m}$ above the substrate. On the second date, 13 transects were sampled within the same $10-\mathrm{m}$ habitat but only transects 1-6 were used for the time comparison because these were the same transects used in the first sampling period. Tapes were analyzed on a VCR (Sony Digital) using randomly selected frames and points on clear acetate sheets placed over the monitor screen. Substrate types under each point were identified. Sampling area per frame was approximately $0.075 \mathrm{~m}^{2}$ (25 by $30 \mathrm{~cm}$ ). Number of points per frame, number of frames per transect, and number of transects per site were examined. Initially 10 frames per transect were used and number of points per frame was varied. This followed protocol from previous work conducted at the study site (C. L. Hunter, unpubl. data). Transect line was the sampling unit with frames treated as subsamples. It should be noted that logistical and financial constraints prevented us from testing all methods across all sites. Therefore, methods were tested in heterogeneous habitats (range of coral cover 34 to $55 \%$ ) that were considered the worst-case scenario with respect to sampling variation.

\section{Cost Analyses}

Each method was assessed in terms of the quantity of data gathered per survey as well as the time required to collect and process the data. This produced a common unit of data points per 1-hr dive (1 survey). To compare methods over time a cost per data point per survey was calculated for four different survey scenarios (1 survey, 10 surveys, 50 surveys, and 100 surveys). This comparison included equipment setup costs, consumables (e.g., film, tape, etc.), labor, and logistical considerations (e.g., dive vessel charter, per diem, vehicle rental, air fare) in relation to sampling distance from the marine laboratory. Administrative costs were assumed to be equal among the methods, so only the actual costs for the field survey and data analysis were included.

\section{Statistical Analysis}

Database storage and initial analysis was conducted in Statistica 6.0 (StatSoft 2001). Two separate analyses were conducted: determination of precision of field techniques sampled over a short temporal scale (Sale 1997) and power analysis of previous and current studies. Percentage data were subjected to an arcsin-square root transformation before testing. Paired $t$-tests were used in the precision comparisons instead of a repeatedmeasures analysis of variance (ANOVA) due to the unequal sample sizes among different transect lengths. Our estimation of statistical power for previous studies used methods described in Zar (1999: chapter 12, equation 12.43). For the current study, power estimation for repeated measures and nested twoway ANOVA, where a minimum detectable difference or effect size of $10 \%$ absolute change in coral cover was specified, we used Zar (1999: chapter 12, equation 12.45). In each case, power was also verified using the Power module in Statistica 6.0.

\section{RESULTS}

\section{Previous Monitoring Studies in Hawai'i}

Previous studies, with the exception of the Kahe Point monitoring effort (Coles 1998), generally showed low statistical power to detect change due to high variability within a site and small sample size (Table 3). Statistical power to detect change of 0.95 was obtained for the Kahe Point study, which used fixed photoquadrats. Fixed photoquadrats provide additional information on recruitment, growth, and mortality of individual 
TABLE 3

Estimation of Statistical Power from Historical Data Sets

\begin{tabular}{lcccccrr}
\hline \hline Study Area/Factor & MSE & MSG & DFG & DFE & $\lambda$ & $\phi$ & Power \\
\hline $\begin{array}{l}\text { Planar Point Intercept } \\
\quad \text { Honolua/Time } \times \text { Site }\end{array}$ & 0.036 & 0.061 & 4 & 240 & 2.82 & 0.75 & 0.23 \\
$\quad \begin{array}{l}\text { Kahekili/Time } \times \text { Site } \\
\quad \text { Puamana/Time } \times \text { Site }\end{array}$ & 0.074 & 0.171 & 8 & 120 & 10.41 & 1.08 & 0.58 \\
$\begin{array}{l}\text { Olowalu/Time } \times \text { Site } \\
\text { Photoquadrat } \\
\quad \text { Molokini/Time } \times \text { Depth }\end{array}$ & 0.015 & 0.077 & 4 & 112 & 16.92 & 1.84 & 0.92 \\
$\begin{array}{l}\text { Fixed Photoquadrats } \\
\text { Kahe/Time } \times \text { Site }\end{array}$ & 0.549 & 0.499 & 8 & 1553 & -0.73 & NA & 0.00 \\
\hline
\end{tabular}

Note: MSE, mean square error; MSG, mean square group; DFG, degrees of freedom group; DFE, degrees of freedom error.

TABLE 4

Precision of Repeated Measures for Current Study

\begin{tabular}{|c|c|c|c|c|c|c|c|c|c|}
\hline Method & Site & Date 1 & Date 2 & $\begin{array}{l}\mathrm{TL} \\
(\mathrm{m})\end{array}$ & $n$ & & $\begin{array}{c}\text { Mean \% } \\
\text { Difference }\end{array}$ & SD & $\% \mathrm{CC}$ \\
\hline \multirow[t]{2}{*}{ PPI } & \multirow[t]{2}{*}{ Kāne'ohe } & 2 Dec. 1998 & 4 Dec. 1998 & 10 & 17 & & 10.6 & 11.8 & 47.6 \\
\hline & & 2 Dec. 1998 & 4 Dec. 1998 & 25 & 31 & & 10.9 & 9.7 & 33.5 \\
\hline \multirow{9}{*}{ Photoquad } & \multirow[t]{2}{*}{ Kāne'ohe } & 2 Dec. 1998 & 4 Dec. 1998 & 10 & 20 & & 10.0 & 14.6 & 55.1 \\
\hline & & 2 Dec. 1998 & 4 Dec. 1998 & 25 & 72 & & 15.9 & 9.8 & 39.9 \\
\hline & \multirow{6}{*}{ Kāne‘ohe } & 17 Dec. 1998 & 18 Dec. 1998 & $10^{a}$ & 20 & & 7.5 & 7.6 & 41.7 \\
\hline & & 17 Dec. 1998 & 18 Dec. 1998 & $25^{a}$ & 50 & & 8.9 & 6.7 & 40.5 \\
\hline & & 17 Dec. 1998 & 18 Dec. 1998 & $10^{b}$ & 10 & Same obs. & 7.5 & 7.6 & \\
\hline & & 17 Dec. 1998 & 18 Dec. 1998 & $10^{b}$ & 10 & Diff. obs. & 10.4 & 10.0 & \\
\hline & & 17 Dec. 1998 & 18 Dec. 1998 & $25^{b}$ & 25 & Same obs. & 8.9 & 6.7 & \\
\hline & & 17 Dec. 1998 & 18 Dec. 1998 & $25^{b}$ & 25 & Diff. obs. & 8.3 & 5.5 & \\
\hline & Molokini & 10 Oct. 1998 & 11 Oct. 1998 & 50 & 32 & & 23.7 & 18.1 & 35.2 \\
\hline
\end{tabular}

Note: PPI, planar point intercept; TL, transect length; $n$, number of quadrats per transect; SD, standard deviation; \%CC, percentage coral cover.

$a$ Pins placed every $2 \mathrm{~m}$ to reduce transect movement.

${ }^{b}$ Same transects used but different observers on photo analysis.

coral colonies (Hughes 1996, Coles 1998). Puamana had very high statistical power to detect change $(P=0.92)$ but was characterized by low coral cover $(<15 \%)$. Honolua $(P=0.23)$ and Kahekili $(P=0.58)$ had low to moderate statistical power to detect change, with coral cover from 25 to $55 \%$, respectively. Statistical power to detect change at Olowalu $(P=0.0)$ was very low because of a patchy coral distribution characterized by a spur and groove reef with stands of high coral cover $(45-50 \%)$ interspersed with sand channels. Photoquadrats used at Molokini also had very low statistical power to detect change $(P=0.0)$, with moderate coral cover $(35 \%)$.

\section{Evaluation of Sampling Designs for Current Study}

PRECISION OF REPEATED SAMPLING USING VISUAL ESTIMATION, PLANAR POINT INTERCEPT, AND PHOTOQUADRATS. Repeat photoquadrats and point-intercept quadrat data showed high variability and consequently low precision (Table 4). Longer transects had higher mean percentage difference between quadrats (e.g., $25 \mathrm{~m}$ at Kāne'ohe: $15.9 \pm$ $9.8 \%)$ than shorter transects at the same location (e.g., $10 \mathrm{~m}$ at Kāne'ohe: $10.0 \pm$ $14.6 \%)$. Variability for both transect lengths (10 m: $7.5 \pm 7.6 \%$ and $25 \mathrm{~m}: 8.9 \pm 6.7 \%$ ) was reduced by placing temporary pins every 


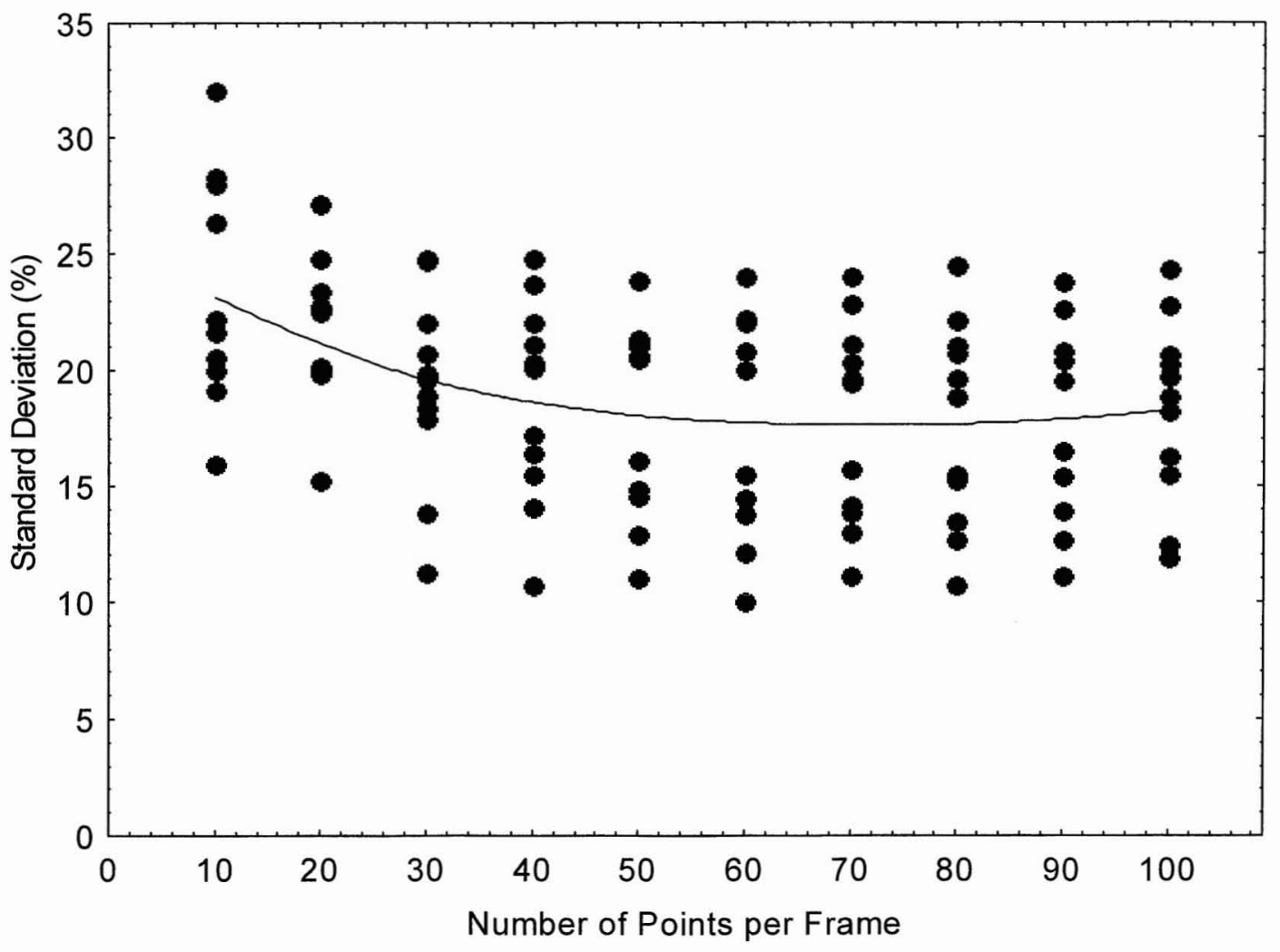

FIGURE 2. Relationship between standard deviation of mean coral cover versus number of points sampled per frame for transects surveyed in Hanauma Bay.

$2 \mathrm{~m}$ along the transect. The pins reduced transect movement during the survey and allowed more accurate repositioning of the line during subsequent surveys. At Molokini, transect length of $50 \mathrm{~m}$ had the lowest precision with the highest mean percentage difference $(23.7 \pm 18.1 \%)$ among quadrats.

Photoquadrats produced significantly higher estimates of coral cover than planar point intercept for the same quadrats sampled (10-m transect, $t=-2.7$, df $=9, P=0.025$; $25-\mathrm{m}$ transect, $t=-2.3, \mathrm{df}=16, P=0.032$ ). Mean percentage difference between comparable quadrats, however, was quite similar between methods (Table 4). Variability between quadrats for the $10-\mathrm{m}$ transect $(10.6 \%$ for planar point intercept versus $10.0 \%$ for photoquadrat) was more comparable than mean percentage differences for the $25-\mathrm{m}$ transect $(10.9 \%$ for planar point intercept versus $15.9 \%$ for photoquadrat). Neither method, however, yielded satisfactory precision. Variability between observers analyzing the same data was low for both transect lengths (Table 4).

PRECISION OF DIGITAL VIDEO TRANsECTs. Plotting standard deviation against number of points per frame indicated that optimum number of points was approximately 50 per frame (Figure 2). This was illustrated by the weighted least squares curve and consequently the variation leveling off at about 50 points per frame. Another approach to determining optimal number of points per frame was to examine the interaction term in a two-way ANOVA for transects sampled two times in succession. Theoretically, trends in coral cover should be reasonably similar for the two samples. Estimates from 10 points per frame showed a different trend in coral cover between the two samples compared with 50 and 100 points sampled per frame 


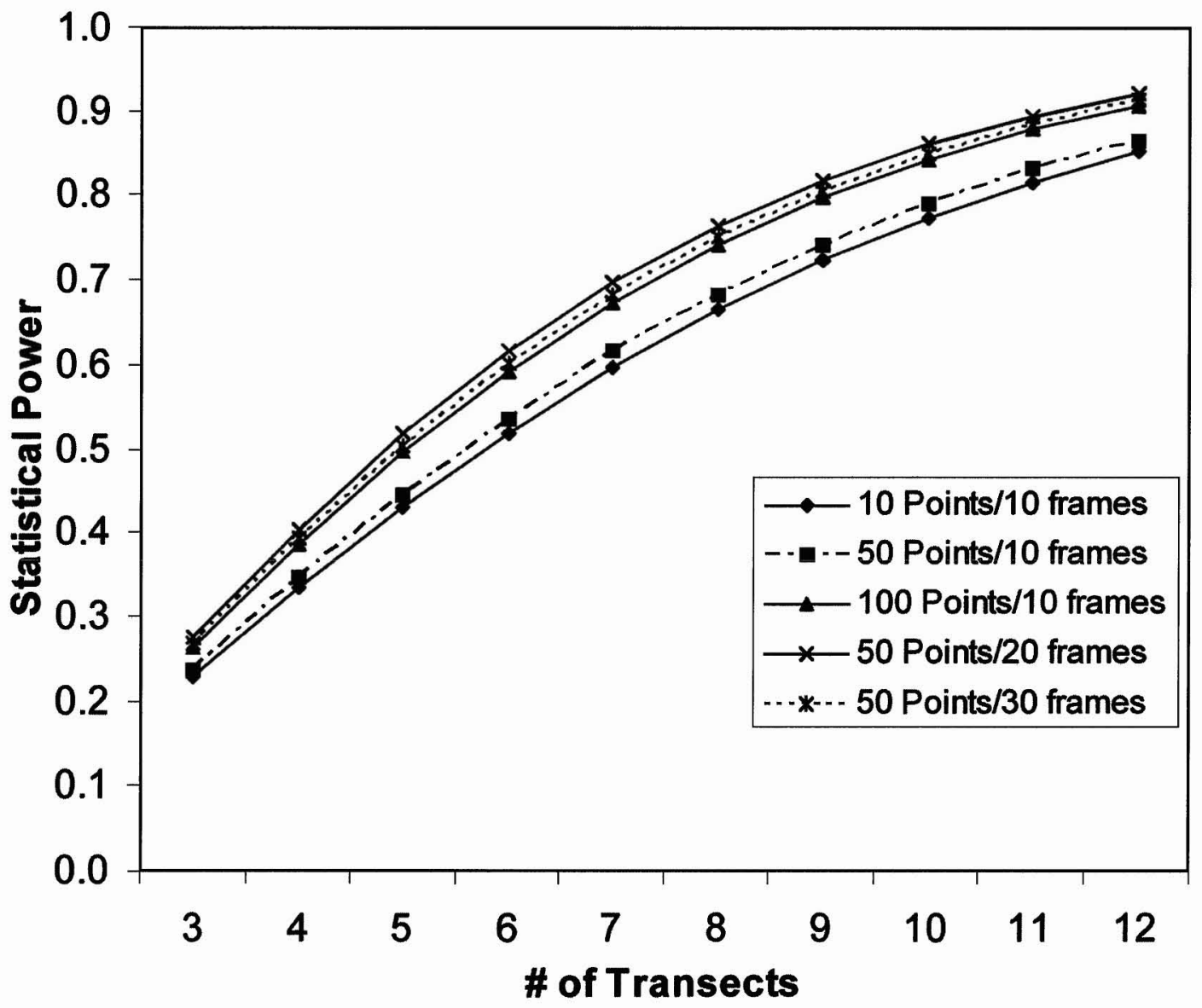

FIGURE 3. Power analysis for number of transects with different numbers of points per frame and different number of frames per transect.

$(F=8.29 ; \mathrm{df}=2,20 ; P<0.0024)$. In other words, use of fewer points can lead to misinterpretation of a trend.

To examine how accurately the point method characterized true substrate cover we mapped out the coral cover using visual estimation with a grid placed on the screen (see Dethier et al. 1993). A similarity matrix was constructed and different observers had very similar estimates ( 95\%) using the visual technique. These values also corresponded well to the estimates from 50 and 100 points per frame ( $>85 \%$ similarity). In contrast, estimates from 10 points per frame had less than $80 \%$ similarity with the other estimation techniques. Though the sample size was small ( $n=10$ frames) it appears that 50 and 100 points per frame provided a reasonable estimate of coverage and was a more accurate description of the benthos than estimates from 10 points per frame.

STATISTICAL POWER ANALYSIS FOR DIGITAL video. Statistical power curves were constructed for the number of points per frame and number of frames per transect using methods described by Zar (1999). The target sample size (number of transects) was set to detect an absolute change of $10 \%$ (effect size) in coral cover across two time periods. Number of frames was more important in increasing statistical power than number of points though the difference was not substantial (Figure 3). For example, the statistical power for 50 points using 20 frames is higher 
TABLE 5

Comparison of Time and Monetary Costs Associated with Each Method in Relation to Sampling Distance

\begin{tabular}{|c|c|c|c|c|c|c|c|c|c|}
\hline \multirow{2}{*}{$\begin{array}{l}\text { Proximity to } \\
\text { Marine } \\
\text { Laboratory }\end{array}$} & \multirow{2}{*}{$\begin{array}{c}\text { Area } \\
\text { Sampled } \\
\left(\mathrm{m}^{2}\right)\end{array}$} & \multirow[b]{2}{*}{ Points ${ }^{a}$} & \multirow{2}{*}{$\begin{array}{c}\text { Total } \\
\text { Points/ } \\
\text { Survey }\end{array}$} & \multirow{2}{*}{$\begin{array}{c}\text { Total Time } \\
\text { Survey } \\
\text { (min) }\end{array}$} & \multirow{2}{*}{$\begin{array}{c}\text { Total } \\
\text { Cost }(\$) / \\
\text { Survey }\end{array}$} & \multicolumn{4}{|c|}{ Cost $(\$)$ per data point per survey ${ }^{d}$} \\
\hline & & & & & & 1 survey & 10 surveys & 50 surveys & 100 surveys \\
\hline \multicolumn{10}{|c|}{ Close site $(<10 \mathrm{~km})$} \\
\hline Visual estimate & 15 & 100 & 1,500 & 135 & 547 & 0.36 & 0.31 & 0.31 & 0.31 \\
\hline Visual-PPIe & 12 & 81 & 972 & 108 & 542 & 0.56 & 0.48 & 0.47 & 0.47 \\
\hline Photoquadrat & 18 & 50 & 1,800 & 294 & 4,335 & 2.41 & 0.49 & 0.32 & 0.30 \\
\hline Digital video & 35 & 10 & 2,000 & 620 & 5,804 & 2.90 & 0.54 & 0.33 & 0.30 \\
\hline Digital video & 35 & 50 & 10,000 & 1,580 & 5,964 & 0.60 & 0.12 & 0.08 & 0.08 \\
\hline Digital video & 35 & 100 & 20,000 & 2,520 & 6,121 & 0.31 & 0.07 & 0.05 & 0.05 \\
\hline \multicolumn{10}{|c|}{ Intermediate site $(10-50 \mathrm{~km})$} \\
\hline Visual estimate & 15 & 100 & 1,500 & 135 & 765 & 0.51 & 0.46 & 0.46 & 0.45 \\
\hline Visual-PPI ${ }^{e}$ & 12 & 81 & 972 & 108 & 760 & 0.78 & 0.70 & 0.70 & 0.70 \\
\hline Photoquadrat & 18 & 50 & 1,800 & 294 & 4,553 & 2.53 & 0.61 & 0.44 & 0.42 \\
\hline Digital video & 35 & 10 & 2,000 & 620 & 6,022 & 3.01 & 0.65 & 0.44 & 0.41 \\
\hline Digital video & 35 & 50 & 10,000 & 1,580 & 6,182 & 0.62 & 0.15 & 0.10 & 0.10 \\
\hline Digital video & 35 & 100 & 20,000 & 2,520 & 6,339 & 0.32 & 0.08 & 0.06 & 0.06 \\
\hline \multicolumn{10}{|c|}{ Remote site $(>50 \mathrm{~km})$} \\
\hline Visual estimate & 15 & 100 & 1,500 & 135 & 2,002 & 1.33 & 1.28 & 1.28 & 1.28 \\
\hline Visual-PPI ${ }^{e}$ & 12 & 81 & 972 & 108 & 1,997 & 2.06 & 1.98 & 1.97 & 1.97 \\
\hline Photoquadrat & 18 & 50 & 1,800 & 294 & 5,790 & 3.22 & 1.30 & 1.13 & 1.11 \\
\hline Digital video & 35 & 10 & 2,000 & 620 & 7,259 & 3.63 & 1.26 & 1.05 & 1.03 \\
\hline Digital video & 35 & 50 & 10,000 & 1,580 & 7,419 & 0.74 & 0.27 & 0.23 & 0.22 \\
\hline Digital video & 35 & 100 & 20,000 & 2,520 & 7,576 & 0.38 & 0.14 & 0.12 & 0.12 \\
\hline
\end{tabular}

${ }^{a}$ Number of points per quadrat/frame.

${ }^{b} \mathrm{l}$-hr dive.

c Included data collection and analysis.

${ }^{d}$ Costs were prorated for equipment, supplies, labor, and logistics.

${ }^{e}$ Planar point intercept.

than that for 100 points using 10 frames even though the total number of points examined is the same. This is primarily due to the fact that more frames sample a larger portion of the habitat, which incorporates more of the heterogeneity of the substrate. A sample size of 10 transects per site appeared to be adequate for detecting an absolute change in coral cover with high statistical power of 0.8 using the convention set by Cohen (1988).

ANALYSIS OF TIME AND MONETARY costs. Digital video methodology produced far more data per 1-hr dive (e.g., 50 points per frame generated 10,000 points) than visual estimation (1500 points per dive), planar point intercept (972 points per dive), or photoquadrats (1800 points per dive) (Table 5). Digital video had the highest initial setup cost at over $\$ 5000$ and consequently the highest cost per initial survey ( $>$ \$5800). Comparison of methods over time, however, indicated that the digital video methods were the most costeffective (range, $\$ 0.05-\$ 0.30$ per data point) after 100 surveys at the close site (Table 5). In contrast, visual estimation techniques were the most expensive method (range, \$0.31$\$ 0.47$ ) per data point after 100 surveys at the close site. Photoquadrats were intermediate and cost approximately $\$ 0.30$ per data point after 100 surveys. The cost-effectiveness of the digital video method compared with other techniques increased in more remote locations where logistical expenses were incurred. Finally, digital video sampled almost twice the area $\left(35 \mathrm{~m}^{2}\right)$ of the next closet method (photoquadrat: $18 \mathrm{~m}^{2}$ ), increasing the spatial inference of the results (Table 5).

\section{DISCUSSION}

Selection of an appropriate sampling protocol to detect change in benthic cover depends on 
numerous regional factors such as the variability of the habitat, oceanographic conditions, and time and monetary constraints. Statistical power to detect change was generally low with previous sampling designs utilized in Hawai'i. Some techniques are only suitable for delineating major changes $(>90 \%)$ in coral cover between yrs. The low statistical power of the previous methods was primarily due to low precision from the longer transects coupled with small sample size. The fixed photoquadrats at Kahe Point, however, had high precision and high statistical power to detect change using a repeatedmeasures design but was limited in spatial inference due to the small sampling area (see Aronson and Swanson 1997).

Digital video transects incorporate a larger spatial area than previous methods and consequently capture more of the spatial variance within reefs (Aronson and Swanson 1997, Vogt et al. 1997). This study indicated that 50 random points per frame was adequate to accurately describe the habitat, and increasing the number of frames per transect to 20-30 increased statistical power to detect change. Using a shorter transect line (sample unit) to increase precision was also preferred as indicated by the fieldwork with the quadrats. Precision at the level of the transect is still a concern and will vary due to differences in line deployment, camera orientation, frame selection, and random point generation. Preliminary results from current studies, however, indicate that this measurement error is on average less than $3 \%$ (E.B., E.C., and K.R., unpubl. data).

Visual estimation techniques had the lowest start-up costs but did not permit image archiving needed for later reanalysis (i.e., quality assurance/quality control) and/or to address additional questions (e.g., Carleton and Done 1995). Digital video required the largest initial investment but generated the greatest number of data points per survey. This technique was cost-effective if capital investment was offset by a large number of surveys (e.g., \$0.08 per data point using 50 points per frame after 100 surveys) (Table 5). Another consideration is the cost of operating in remote locations where travel, per diem, and boat charter fees are the most crucial factors. Costs per site per day ranged from $\$ 2130$ at sites adjacent to the marine laboratory, to nearly $\$ 4290$ for distant sites on neighboring islands. In these situations the cost of getting to the site is the most expensive parameter, so the quantity of field data collected per unit time is critical. Digital video became more cost-effective in comparison with other methods at these remote sites.

Based on the results from the evaluation procedure, two different and complementary methods were selected by CRAMP for benthic monitoring. Digital video over a large area using randomly stratified fixed transects was used as the primary technique to measure changes in benthic cover over time. This method is based on randomly selected images along each transect, so it tells us little about recruitment or the fate of individual colonies. Another limitation is the reduced taxonomic resolution of the substrate (Carleton and Done 1995, Tomkins et al. 1999). Consequently, high-resolution fixed photoquadats with high precision and statistical power were installed as the second method to track the growth, recruitment, and mortality of coral colonies and other benthic organisms (Hughes 1996).

Digital video was used to measure changes in coral cover by surveying 10 permanent (fixed) transects at two depths (e.g., $3 \mathrm{~m}$ and $10 \mathrm{~m}$ ). The decision to employ fixed transects for the CRAMP study was based on previous studies (Green and Smith 1997) and our own field experience. Fixed transects have been shown to reduce the temporal variance in sampling reef communities and as a result provide better statistical power to document change compared with random sampling with the same sample size (Rogers et al. 2002). Further, the high-wave-energy conditions found along the Hawaiian coastlines create difficulties in field sampling that are greatly reduced through use of well-marked permanent transects and permanent photoquadrats. Finally, several yr of sampling coupled with the new NOAA habitat maps for Hawai'i indicated that the fixed transects were fairly representative of the surrounding habitat. These transects were initially selected at ran- 
dom from a pool of 50 possible starting points located in a 2 by $100 \mathrm{~m}$ grid along a depth contour. To assist in relocating the transect grid a central spine of 11 pins $(0-100 \mathrm{~m})$ was installed every $10 \mathrm{~m}$ with global positioning system (GPS) marks at the beginning and end. Each transect was $10 \mathrm{~m}$ long and analyzed using 20 randomly selected nonoverlapping video frames, with 50 randomly selected points per frame. Total area sampled at each depth is $35 \mathrm{~m}^{2}$ (Table 5). Sampling frequency is once a year at each site. A repeated-measures ANOVA design is being used, and frames per transect are treated as subsamples along a transect. This protocol is sufficient to detect an absolute change of $10 \%$ in coral cover over time with high statistical power $(P>0.8$ at $\alpha \leq 0.05)$ across a variety of habitats in Hawai'i.

The fixed photoquadrats examine growth, recruitment, and mortality of individual corals at a smaller spatial scale (Porter and Meier 1992). Five randomly selected photoquadrats at each depth contour were established with one pin in each corner to ensure accurate repositioning of the frame. The frame samples $0.33 \mathrm{~m}^{2}$ of the substrate at a height of $0.5 \mathrm{~m}$ from the bottom, with the total area sampled at each depth being $1.7 \mathrm{~m}^{2}$. Images of corals are traced and digitized for two-dimensional estimates of aerial coverage. Sampling frequency is annually.

In summary, the first phase of any benthic monitoring program should be directed at development and evaluation of statistically valid sampling protocols that meet the local requirements. Second, benthic monitoring methods will vary regionally due to differences in coral reef community composition, oceanographic characteristics, and economic constraints. Finally, the focus of benthic monitoring protocols should be on the ability to detect change regardless of method selected.

\section{ACKNOWLEDGMENTS}

We thank the staff and volunteers of the $\mathrm{Ha}$ wai'i Institute of Marine Biology, the $\mathrm{Pa}$ cific Whale Foundation, Earthwatch, and the State of Hawaici Division of Aquatic Resources for their participation and support.
Cindy Hunter provided assistance with the video work in Hanauma Bay. Thanks also go to three anonymous reviewers whose constructive comments improved the paper considerably.

\section{Literature Cited}

Aronson, R. B., and D. W. Swanson. 1997. Video surveys of coral reefs: Uni- and multivariate applications. Proc. 8th Int. Coral Reef Symp. 2:1441-1446.

Aronson, R. B., P. J. Edmunds, W. F. Precht, D. W. Swanson, and D. R. Levitan. 1994. Large-scale, long-term monitoring of Caribbean coral reefs: Simple, quick, inexpensive techniques. Atoll Res. Bull 421: 1-19.

Brown, E. K. 1999. Earthwatch field report. Pacific Whale Foundation, Kīhei, Hawai'i.

Carleton, J. H., and T. J. Done. 1995. Quantitative video sampling of coral reef benthos: Large-scale application. Coral Reefs 14:35-46.

Cohen, J. 1988. Statistical power analysis. 2nd ed. L. Erlbaum Assoc., Hillsdale, New Jersey.

Coles, S. L. 1998. Annual report. Kahe generating station National Pollution Discharge Elimination System monitoring report for 1997. AECOS, Inc., Kailua, Hawaici.

Coyer, J., and J. D. Witman. 1990. The underwater catalog: A guide to methods in underwater research. Shoals Marine Laboratory, Cornell University and New York Sea Grant, Ithaca, New York.

Dethier, M. N., E. S. Graham, S. Cohen, and L. M. Tear. 1993. Visual versus randompoint percent cover estimations: 'Objective' is not always better. Mar. Ecol. Prog. Ser. 96:93-100.

Dollar, S. J. 1993. Recurrent storm damage and recovery: A long-term study of coral communities in Hawai'i. Coral Reefs 12: 223-233.

Done, T. J., and R. E. Reichelt. 1998. Integrated coastal zone and fisheries ecosystem management: Generic goals and performance indices. Ecol. Appl. 8 (1): S110-S118.

Evans, C. W., J. E. Maragos, and P. F. 
Holthuis. 1986. Reef corals in Kaneohe Bay: Six years before and after termination of sewage discharges (Oahu, Hawaiian Archipelago). Pages 76-90 in P. L. Jokiel, R. H. Richmond, and R. A. Rodgers, eds. Coral reef population biology. Hawaii Inst. Mar. Biol. Tech. Rep. 37.

Fairweather, P. G. 1991. Statistical power and design requirements for environmental monitoring. Aust. J. Mar. Freshwater Res. 42:555-567.

Ginsburg, R., P. Kramer, J. Lang, P. Sale, and R. Steneck. 1999. Rapid assessment of corals, algae, and fish on reefs of the western Atlantic and Gulf of Mexico (AGRRA). Proceedings, International Conference on Scientific Aspects of Coral Reef Assessment, Monitoring, and Restoration, 14-16 April 1999, Fort Lauderdale, Florida. National Coral Reef Institute, Nova Southeastern University, Fort Lauderdale, Florida.

Green, R. H., and S. R. Smith. 1997. Sample program design and environmental impact assessment on coral reef. Proc. 8th Int Coral Reef Symp. 2:1459-1464.

Grigg, R. W., and S. J. Dollar. 1990. Natural and anthropogenic disturbance on coral reefs. Pages 439-452 in Z. Dubinsky, ed. Ecosystems of the world. 25. Coral reefs. Elsevier, Amsterdam, The Netherlands.

Hughes, T. P. 1996. Demographic approaches to community dynamics: A coral reef example. Ecology 77 (7): 22562260.

Hughes, T. P., and J. H. Connell. 1999. Multiple stressors on coral reefs: A longterm perspective. Limnol. Oceanogr. 44 (3): 932-940.

Hunter, C. L., and C. W. Evans. 1993. Reefs of Kaneohe Bay, Hawaii: Two centuries of Western influence and two decades of data. Bull. Mar. Sci. 57:501-515.

Jokiel, P. L., E. K. Brown, A. Friedlander, S. K. Rodgers, and W. R. Smith. 2004. Hawai'i Coral Reef Assessment and Monitoring Program: Spatial patterns and temporal dynamics in reef coral communities. Pac. Sci. 58:159-174.

Maragos, J. E. 1972. A study of the ecology of Hawaiian reef corals. Ph.D. diss., University of Hawai'i at Mānoa, Honolulu.
Miller, S. L., and D. W. Swanson. 1999. Rapid assessment methods for monitoring marine protected areas in the Florida Keys National Marine Sanctuary: Program design and effects of Hurricane George on reefs in the middle and lower Keys. Proceedings, International Conference on Scientific Aspects of Coral Reef Assessment, Monitoring, and Restoration, 14-16 April 1999, Fort Lauderdale, Florida. National Coral Reef Institute, Nova Southeastern University, Fort Lauderdale, Florida.

Ohlhorst, S. L., W. D. Liddell, R. J. Taylor, and J. M. Taylor. 1988. Evaluation of reef census techniques. Proc. 6th Int. Coral Reef Symp. 2:319-324.

Pastorok, R. A., and G. R. Bilyard. 1985. Effects of sewage pollution on coral-reef communities. Mar. Ecol. Prog. Ser. 21: 175-189.

Porter, J. W., and O. W. Meier. 1992. Quantification of loss and change in Floridian reef coral populations. Am. Zool. 32:625-640.

Reed, A. S. 1980. Sampling and transecting techniques on tropical reef substrates. Pages 71-89 in Environmental survey techniques for coastal water assessment. Conference Proceedings, University of Hawai'i Sea Grant College Program. Cooperative Report UNIHI-SEAGRANTCR-80-01.

Rogers, C. R., G. Garrison, R. Grober, Z. M. Hillis, and M. A. Franke. 1994. Coral reef monitoring manual for the Caribbean and western Atlantic. National Park Service, Virgin Islands National Park, U.S. Virgin Islands.

Rogers, C. R., J. Miller, and R. J. Waara. 2002. Tracking changes on a reef in the U.S. Virgin Islands with videography and SONAR: A new approach. Proc. 9th Int. Coral Reef Symp. 2:1065-1069.

Sale, P. F. 1997. Visual census of fishes: How well do we see what is there? Proc. 8th Int. Coral Reef Symp. 2:1435-1440.

StatSoft. 2001. Statistica 6.0 system reference. StatSoft, Inc., Tulsa, Oklahoma.

Sweatman, H., ed. 1997. Long-term monitoring of the Great Barrier Reef. Status Report No. 2. Australian Institute of 
Marine Science, Townsville, Queensland, Australia.

Tomkins, P. A., D. K. Bass, D. A. Ryan, and H. Sweatman. 1999. Video identification of benthic organisms: How accurate is it? Proceedings, International Conference on Scientific Aspects of Coral Reef Assessment, Monitoring, and Restoration, 14-16 April 1999, Fort Lauderdale, Florida. National Coral Reef Institute, Nova Southeastern University, Fort Lauderdale, Florida.

Vogt, H., A. R. F. Montebon, and M. L. R. Alcala. 1997. Underwater video sampling: An effective method for coral reef surveys? Proc. 8th Int. Coral Reef Symp. 2:14471452.

Wheaton, J. L., P. Dustan, W. C. Jaap, and J. W. Porter. 1999. EPA Coral/Hardbottom Monitoring Project, Florida Keys
National Marine Sanctuary. Proceedings, International Conference on Scientific Aspects of Coral Reef Assessment, Monitoring, and Restoration, 14-16 April 1999, Fort Lauderdale, Florida. National Coral Reef Institute, Nova Southeastern University, Fort Lauderdale, Florida.

Woodley, J. D., and D. M. Linton. 1999. The Caribbean Coastal Marine Productivity (CARICOMP) Program. Proceedings, International Conference on Scientific Aspects of Coral Reef Assessment, Monitoring, and Restoration, 14-16 April 1999, Fort Lauderdale, Florida. National Coral Reef Institute, Nova Southeastern University, Fort Lauderdale, Florida.

Zar, J. 1999. Biostatistical analysis. 4th ed. Prentice-Hall, Upper Saddle River, New Jersey. 